\title{
Compliance with standard treatment guidelines in the management of hypertension: a review of practice of healthcare workers in Potchefstroom, North West Province, South Africa
}

\author{
Peter Rapula Siko ${ }^{\mathrm{a}}$ and Claire van Deventer ${ }^{\mathrm{a} *}$ (D) \\ ${ }^{a}$ Family Medicine and Rural Health, University of the Witwatersrand, Potchefstroom, South Africa \\ *Corresponding author, email: cvandeventer@nwpg.gov.za
}

Introduction: Hypertension is a leading lifestyle disease and major cause of morbidity and mortality in South Africa, and globally. Standard Treatment Guidelines are issued in this country to assist healthcare workers in the diagnosis and management thereof. Considering the debilitating effects caused by hypertension, the objectives were to find out whether healthcare workers diagnose and manage hypertension correctly in terms of compliance with the guidelines.

Method: A records audit was done of patients newly diagnosed with hypertension between April 2009 and March 2011 from a purposeful sample of clinics and the local hospital, using a data collection tool. The study included all adults above 18 years and excluded all patients with co-morbidity at the time of diagnosis.

Results: A total of 475 clinical encounters were analysed. Compliance with diagnosis based on the clinical guideline was $56 \%$ and $75 \%$ by nurses and doctors respectively. Drug management by doctors was less adherent to guidelines (56.6\%) than that of nurses (63.6\%) There was overall poor compliance with non-drug management.

Conclusions: As the adherence to hypertension guidelines in primary care by healthcare workers in general is suboptimal, continuous professional development in terms of diagnosis, drug and non-drug management is essential.

Keywords: clinical treatment guidelines, guideline compliance, healthcare workers, hypertension

\section{Introduction}

Evidence-based medicine is at the forefront of safe medical practice. Major research is summarised in the form of guidelines for ease of use by practitioners who are too busy to confirm the most recent information from major trials. Many practitioners are not aware of these guidelines and some are aware of them but fail to follow them by choosing agents inconsistent with the national guidelines. ${ }^{1}$ General practitioners (GPs) accept an elevated BP among their clients contrary to the targets set by international guidelines. ${ }^{2}$

The Republic of South Africa (RSA) accepted the Essential Drugs Programme's Essential Drug List (EDL) concept within a National Drug Policy (NDP) in 1996., This was intended to promote rational drug use and reduce pharmaceutical costs, as well as to rationalise selection, procurement and the utilisation of drugs through the use of different guidelines for primary health care (PHC), hospital adult and paediatric patients'Standard Treatment Guidelines (STGs). Essential medicines are defined as 'those that satisfy the priority health needs of the population' with it being a national responsibility to identify medicines which are 'essential'. ${ }^{3}$ Anti-hypertensive drugs that are included in the national hypertensive guidelines form part of the EDL.

According to the Global Burden of Disease study (GBD) in 2010, of 52.8 million deaths, 34.5 million (65\%) could be attributed to non-communicable diseases (NCDs). Some $54 \%$ of disabilityadjusted life years worldwide were caused by NCDs in 2010 compared with only $43 \%$ in 1990.5 In South Africa currently $30.4 \%$ of the adult population has hypertension, which requires a simple approach to assessment and treatment. ${ }^{6}$
Hypertension (HPT) is diagnosed as systolic blood pressure (SBP) $>140 \mathrm{mmHg}$ and diastolic blood pressure (DBP) $>90 \mathrm{mmHg}$ on three separate occasions. ${ }^{2,7}$ The overall prevalence of HPT in the global adult population in 2000 was 972 million whereas 1.56 billion are projected to have developed this condition by $2025 .{ }^{8}$ Early detection and sufficient treatment of arterial HPT improves patient prognosis and may contribute to cost containment for healthcare providers. Current studies (HOT ${ }^{9}$ SHEP ${ }^{10}$ and STOPHypertension ${ }^{11}$ ) have shown impressively that efficient antihypertensive therapy will decrease the incidence of stroke and cardiac events by up to $51 \%$ and significantly reduce the risk of cardiovascular morbidity and mortality, with more intense BP lowering providing greater risk reductions, namely a $37 \%$ reduced risk of cardiovascular outcomes. Good communication between the physician and the patient lies at the core of the successful management of HPT. Failure to establish effective communication and relations will generally lead to poor adherence to antihypertensive therapy and unsatisfactory control of the raised $\mathrm{BP}$.

According to the 'The Sixth Report on the Joint National Committee on Prevention, Detection, Evaluation, and Treatment of High Blood Pressure (JNC 6)', guidelines are developed based on publication of many new hypertension observational studies and clinical trials. ${ }^{12}$ The 1999 World Health OrganizationInternational Society of Hypertension (WHO-ISH) guidelines provide recommendations that are based on the collective expert interpretation by the guideline sub-committee of the available evidence from epidemiological studies and from clinical trials. ${ }^{13}$ This is in line with the 2011 UN political declaration ${ }^{14}$ on NCDs to achieve the goal of $25 \%$ reduction in 
premature NCD mortality by 2025 (the 25 by 25 goal), which recommends a stepwise approach to clinical management of people at high risk of cardiovascular disease, including changes to healthcare delivery such as shifting of tasks to middle-level health workers when appropriate. South Africa has since introduced clinical associates and provision of fixed-dose combinations of drugs for the prevention of cardiovascular disease. Most of the guidelines developed are for nurse-driven management of non-communicable diseases.

Literature in South Africa shows that the EDL/Standard Treatment Guidelines (STG) enabled nurses to control clinical conditions of $68 \%$ of patients with HPT, $82 \%$ with non-insulin-dependent diabetes mellitus and $84 \%$ with asthma. This management of chronic diseases by nurses removed the burden of $79 \%$ of these patients from district hospitals to the clinics and improved patient adherence from $79 \%$ to $87 \% .^{15}$

In South Africa most of the guidelines are developed for nursedriven management of non-communicable diseases and some national data have shown poor adherence by patients to medication and by physicians to guidelines. ${ }^{16,17}$ During undergraduate and postgraduate $\mathrm{PHC}$ training, nursing students are taught the EDL and STGs and in the DKK district; after new versions of the EDL are released, in-service sessions are arranged by the district pharmacist and family physician.

Given the disturbing statistics associated with NCDs, which include hypertension as the main disease and that several communitybased surveys in South Africa have found that hypertension is usually inadequately diagnosed and poorly treated, ${ }^{18,19}$ it was decided to assess whether HCWs in the Potchefstroom sub-district North West province (SA) comply with the STGs in the diagnosis and management of hypertensive patients.

\section{Methods}

\section{Aim}

- To assess the degree of compliance of HCWs with STGs in the management of hypertensive patients in Potchefstroom sub-district primary health care (PHC).

\section{Objectives}

- To describe the demography of newly diagnosed patients with hypertension at Potchefstroom sub-district for the years 2009 to 2011.

- To assess compliance with the STG in terms of hypertension diagnosis; and

- To assess compliance with management (drug and non-drug) of newly hypertensive patients diagnosed within the study period.

\section{Study design}

A record review with purposeful retrospective sampling was conducted.

\section{Setting}

This was done for the period of April 2009 to March 2011 on newly diagnosed hypertensive patients above 18 years old from four fixed health facilities and Potchefstroom hospital, in the Potchefstroom sub-district. The other facilities were not utilised due to poor data management and administrative support, which would have impacted on the validity of the study.

\section{Participants}

\section{Study population}

All hypertensive patients diagnosed between April 2009 and March 2011 who were above 18 years without co-morbidity of chronic conditions like diabetes mellitus, epilepsy, asthma, tuberculosis and human immunodeficiency virus (HIV) at the time of diagnosis were included. According to the District Health Information System (DHIS) for the period of the study, there were 1710 new cases of hypertension in the subdistrict and the researcher's initial study sample was set at 150 files, representing $10 \%$ of the research population with four clinic visits over a 12-month period.

\section{Inclusion and exclusion criteria}

The study included all adults above 18 years of age who had been diagnosed during the study period and excluded all patients with co-morbidity at the time of diagnosis.

\section{Variables}

Variables included in the data collection tool were the demography of the patients (clinic registration number, research number, age, gender), BMI, BP levels at diagnosis and follow-up, evidence of target organ damage in terms of proteinuria and haematuria as the only available indicators to be assessed, compliance with drug and non-drug management and the category of healthcare worker involved. This information was sourced from the clinic chronic management form found in each file.

The diagnosis of HPT was based on three readings hours or days apart and a qualifying target BP of more than $140 / 90 \mathrm{mmHg}$ for patients without co-morbidities was the criterion. Management was classified according to the steps illustrated in Table 1 and in line with international standards.

Health passports or clinic health books of patients attending Potchefstroom regional hospital as well as the sub-district clinics were collected from the admission department and screened for clients who could meet the research criteria and those who met the standards were included in the study.

\section{Data collection tool/data measurement}

A clinically orientated data collection tool was developed in line with the STG in terms of diagnosis, drug and non-drug management. All the relevant elements related to the diagnosis and management of hypertension in the EDL were included in the tool. The collection of the data was manually retrieved from the notes on the patients' health records in all health facilities.

In order to enlarge the sample and reduce bias, an attempt was made to access the local hospital records.

Table 1: Hypertensive management steps

\begin{tabular}{ll}
\hline Steps & Intervention \\
\hline \multirow{2}{*}{ Immediately } & $\begin{array}{l}\text { Amlodipine for hypertensive emergency blood pressure }> \\
180 / 130 \mathrm{mmHg} \text { or hypertensive urgency blood pressure }> \\
240 / 140 \mathrm{mmHg}\end{array}$ \\
1 & Lifestyle modification only \\
2 & Lifestyle modification and single anti-hypertensive group class \\
3 & Lifestyle modification and two anti-hypertensive group classes \\
4 & Lifestyle modification and three anti-hypertensive group classes \\
\hline 5 & Life style modification and four anti-hypertensive group classes \\
\hline
\end{tabular}


Table 2: Facility prescribing encounters indicating strength of sample

\begin{tabular}{lcc}
\hline Facility & Files & Number of encounters \\
\hline BT Community health centre & 7 & 132 \\
P Community Health Centre & 6 & 170 \\
L clinic & 3 & 74 \\
M clinic & 2 & 37 \\
Hospital files & 3 & 22 \\
\hline
\end{tabular}

Note: The individual clinics and community health centres are abbreviated for confidentiality.

\section{Statistical methods}

All statistical analyses were done using SPSS Statistics Version $22^{\circledR}$ (IBM Corp, Armonk, NY, USA).

\section{Ethics}

The study received ethical clearance from the University of the Witwatersrand, and the North West Department of Health Policy, Planning, Research, Monitoring and Evaluation in July 2013. Files accessed were numbered for confidentiality and anonymity.

\section{Results}

All values are expressed as mean and standard deviation $( \pm \mathrm{SD})$ except where stated. Twenty-one files with 475 encounters were analysed. These were selected from five facilities. The majority of the patients came from both health centres comprising $61.9 \%$ of

Table 3: Mean blood pressure of 21 patients at initial diagnosis the total sample. The facilities that were excluded were omitted due to poor data management and inadequate administrative support. In the strict application of the criteria, it was found that most patients newly diagnosed with hypertension were already on ART, diabetic medication or other chronic treatment and thus had to be excluded. A number of patients in primary health care who qualified using the criteria, and patients diagnosed at the hospital were also included.

Table 2 shows the number of encounters per facilities which were $80 \%$ compliant with the WHO standard on how to investigate drug use in health facilities: 'in drawing a retrospective sample of patient encounters, the basic indicator study calls for a sample of 30 prescribing encounters per health facility, or 100 encounters if prescribing practices in individual facilities are to be compared.12 In four of the five researched facilities, patients' encounters exceeded the WHO standard, which indicates the strength of the sample.

The Kruskal-Wallis test has been used to calculate the $p$-value of significant difference between SBP and DBP at diagnosis at different clinics due to a small sample size as it is difficult to test the assumption of normality due to lack of power (Table 3 ).

The ANOVA has been used (Table 4) due to the large sample size overall. In this case the central limit theorem holds that means are normally distributed and shows a significant difference between SBP $(p=0.002)$ and DBP $(p=0.000)$ at different clinics.

\begin{tabular}{lcccccc}
\hline Factor & $\begin{array}{c}\text { Numbers of } \\
\text { patients }\end{array}$ & $\begin{array}{c}\text { Minimum blood } \\
\text { pressure }\end{array}$ & $\begin{array}{c}\text { Maximum blood } \\
\text { pressure }\end{array}$ & Mean & $\begin{array}{c}\text { Standard deviation } \\
\boldsymbol{p} \text {-value according } \\
\text { to Kruskal-Wallis } \\
\text { test: different clinics }\end{array}$ \\
\hline $\begin{array}{l}\text { Initial systolic blood } \\
\text { pressure }\end{array}$ & 21 & 126 & 154 & 138.48 & 8.76 & 0.803 \\
$\begin{array}{l}\text { Initial diastolic blood } \\
\text { pressure }\end{array}$ & 21 & 69 & 102 & 83.10 & 8.66 & 0.626 \\
\hline
\end{tabular}

Table 4: Mean blood pressure for all encounters

\begin{tabular}{lcccccc}
\hline Factor & $\begin{array}{c}\text { Number of } \\
\text { encounters }\end{array}$ & $\begin{array}{c}\text { Minimum blood } \\
\text { pressure }\end{array}$ & $\begin{array}{c}\text { Maximum blood } \\
\text { pressure }\end{array}$ & Mean & $\begin{array}{c}\text { Standard deviation } \\
\boldsymbol{p} \text {-value according } \\
\text { to ANOVA }\end{array}$ \\
\hline $\begin{array}{l}\text { Systolic blood pressure } \\
\text { Diastolic blood }\end{array}$ & 438 & 70 & 201 & 137.56 & 18.904 & 0.002 \\
pressure & 438 & 44 & 149 & 80.59 & 14.587 & 0.00 \\
\hline
\end{tabular}

Table 5: Systolic and diastolic blood pressure as measured on initial and all subsequent visits

\begin{tabular}{|c|c|c|c|c|c|c|}
\hline Clinic & Variable & $\begin{array}{c}\text { Numbers of } \\
\text { encounters per clinic }\end{array}$ & $\begin{array}{l}\text { Minimum blood } \\
\text { pressure }\end{array}$ & $\begin{array}{l}\text { Maximum blood } \\
\text { pressure }\end{array}$ & Mean & Standard deviation \\
\hline \multirow{2}{*}{ BT } & Systolic blood pressure & 132 & 70 & 200 & 137.56 & 17.73 \\
\hline & Diastolic blood pressure & 132 & 44 & 134 & 80.58 & 13.38 \\
\hline \multirow{2}{*}{ L } & Systolic blood pressure & 75 & 100 & 180 & 136.62 & 18.68 \\
\hline & Diastolic blood pressure & 75 & 49 & 149 & 72.56 & 15.93 \\
\hline \multirow{2}{*}{ M } & Systolic blood pressure & 39 & 110 & 190 & 146.69 & 21.21 \\
\hline & Diastolic blood pressure & 39 & 51 & 118 & 84.53 & 15.26 \\
\hline \multirow{2}{*}{ Hospital } & Systolic blood pressure & 24 & 110 & 162 & 136.79 & 12.98 \\
\hline & Diastolic blood pressure & 24 & 70 & 101 & 85.08 & 8.38 \\
\hline \multirow{2}{*}{$\mathrm{P}$} & Systolic blood pressure & 168 & 101 & 201 & 138.73 & 19.41 \\
\hline & Diastolic blood pressure & 168 & 55 & 128 & 83.36 & 14.03 \\
\hline \multirow{2}{*}{ Consolidated Data } & Systolic blood pressure & 438 & 70 & 201 & 137.56 & 18.90 \\
\hline & Diastolic blood pressure & 438 & 44 & 149 & 80.58 & 14.58 \\
\hline
\end{tabular}


Table 6: Compliance in terms of diagnosis by healthcare workers

\begin{tabular}{lccc}
\hline Healthcare workers & $\begin{array}{c}\text { Encounters per } \\
\text { healthcare worker }\end{array}$ & No (\%) & Yes (\%) \\
\hline Unaccounted & 1 & $1(100)$ & $0(0)$ \\
Doctors & 4 & $1(25)$ & $3(75)$ \\
Professional nurses & 16 & $7(44)$ & $9(56)$ \\
Total & 21 & $9(42)$ & $12(58)$ \\
\hline
\end{tabular}

Table 7: Compliance with drug management by healthcare workers

\begin{tabular}{lccc}
\hline Healthcare workers & $\begin{array}{c}\text { Encounters per } \\
\text { healthcare worker }\end{array}$ & No (\%) & Yes (\%) \\
\hline Unaccounted & 3 & $1(33.3)$ & $2(66.7)$ \\
Doctors & 45 & $20(44.4)$ & $25(56.6)$ \\
Professional nurses & 427 & $136(31.9)$ & $271(63.5)$ \\
\hline Total & 475 & $157(33.1)$ & $298(62.7)$ \\
\hline
\end{tabular}

Though not the focus of the study it was found that $62 \%$ of the sample had controlled BP $(<140 / 90 \mathrm{mmHg})$ whereas $10 \%$ and $28 \%$ had moderate and mild HPT respectively. Hypertensive emergency was recorded in 16 visits representing 8 patients where, in only one, amlodipine $10 \mathrm{mg}$ stat was given. BP control is invariably related to other patient factors that were not assessed in this study.

The average age for the sample ranged between 31 to 85 years with an overall sample average of 52.81 years. The sample was composed of $57 \%$ male and $42 \%$ female patients. Age was adjusted at every birthday during follow-up visits. The majority of the patients came from health centres comprising $61.90 \%$ of the total sample (Tables 5 and 6).

Table 6 reflects compliance in terms of diagnosis by healthcare workers and the nature and characteristic of clinics where the majority of patients are seen by nurses (76\%). In terms of percentages, doctors are seen to diagnose patients correctly $75 \%$ of the time compared with $56 \%$ for nurses, but nurses saw many more patients than doctors.

Compliance with drug management by nurses was superior to that of doctors as shown in Table 7. Step 2 drug management had a total of $105 \mathrm{BP}$ measurement qualifying visits and only 89 (85\%) complied whereas step 3 had 212 BP measurement qualifying visits with 141 (60\%) complying. Step 4, which relates to the use of three drugs, had 62 (48\%) complying and 66 (52\%) non-compliant (Table 7).

The overall non-drug management (55\%) documented in patients' files indicated a severe lack of health promotion and accountability for any factors impacting on hypertension control (Table 8).

\section{Discussion}

There are three broad categories of barriers in clinical practice that can prevent patients from achieving BP control, namely the health system, plus patient-related and physician-related factors. The latter are clinical inertia, poor communication and lack of awareness/knowledge of treatment guidelines. ${ }^{2}$ According to published data of Hayman and Pavlik ${ }^{20}$ a substantial proportion of physicians would not start anti-hypertensive treatment unless the BP exceeded values of $160 / 95$, which is in sharp contrast to the recommendations of the JNC-VI ${ }^{12}$ guidelines (140/90).

The compliance of the physician with guidelines seems to be influenced by knowledge and guideline awareness and by the time span of working in private practice. Awareness of guidelines dropped significantly between physicians who had been in practice for 2 years (33.3\%) and those who had been in practice for more than 20 years (19.5\%). ${ }^{2}$ It was found that GPs are aware of their HPT guidelines but seem not to be sure that they need to follow them in practice. ${ }^{1,2}$ Some $41 \%$ of doctors in the United States of America (USA) who treat patients with HPT had either not heard of the JNC-V guidelines or had heard of the report but were not familiar with the contents and some of the physicians reported limited familiarity with the consensus JNC-V guidelines. ${ }^{21}$ In a German study done from December 1999 to March 2000 only 23.7\% of German physicians were adequately aware of guidelines. ${ }^{2}$ South African doctors and nurses should be well versed in the EDL as it is an integral part of undergraduate teaching and the relatively poor performance in following the different elements of the guidelines is therefore difficult to explain. Specific HCW characteristics were not evaluated as they were in the above studies.

In the eThekwini study done in KwaZulu-Natal ${ }^{4}$ the mean adherence to hypertensive treatment guidelines in state facilities was $22.05 \%$ based on a much larger sample representation of 2100 encounters. Much as they do not compare statistically there is a positive trend towards an increase in compliance in the Potchefstroom study with guidelines by nurses, who are the backbone of PHC.

Overall, physicians said that on average $52.6 \%$ of their patients were attaining ESH-ESC recommended targets and threequarters $(77.4 \%)$ of physicians said that it was a challenge to get their patients to achieve these targets in practice. ${ }^{1,2}$

In SA in KwaZulu-Natal it was shown that when physicians fail to prescribe lifestyle modifications, adequate antihypertensive drug doses, or appropriate drug combinations, inadequate BP control may result. ${ }^{4}$

Correct diagnosis, drug and non-drug management are all elements of the guidelines. The first research objective was to check compliance with diagnosis using the STGs and doctors appropriately diagnosed $75 \%$ correctly with nurses being correct in $58 \%$ of cases. It has to be noted that all patients will have been seen and started on treatment by nurses and referred to the doctor for confirmation

Table 8: Compliance with non-drug management by healthcare workers

\begin{tabular}{|c|c|c|c|c|c|c|c|c|c|}
\hline Healthcare workers & Unaccounted & Diet & Exercise & Health education & None & Treatment compliance & Smoking & Yes & Total \\
\hline Unaccounted & 0 & 1 & 0 & 0 & 2 & 0 & 0 & 0 & 3 \\
\hline Doctors & 0 & 2 & 0 & 12 & 27 & 3 & 1 & 0 & 45 \\
\hline Professional nurses & 16 & 43 & 4 & 52 & 236 & 70 & 4 & 2 & 427 \\
\hline Total $(n)$ & 16 & 46 & 4 & 64 & 265 & 73 & 5 & 2 & 475 \\
\hline Total (\%) & $3.4 \%$ & $9.7 \%$ & $0.8 \%$ & $13.5 \%$ & $55.8 \%$ & $15.4 \%$ & $1 \%$ & $0.4 \%$ & $100.0 \%$ \\
\hline
\end{tabular}


of the diagnosis. At diagnosis a total of nine patients, which represents $42 \%$, were not diagnosed as hypertensive despite meeting all the criteria for a hypertensive diagnosis. This concurs with the SHARE study, which has demonstrated that physicians were hesitant to initiate or take action for elevated BP.'

With the second element of the guidelines, namely drug management, professional nurses (PNs) performed better in the control of BP using drug management during follow-up than they did at diagnosis. This is encouraging as nurses see the majority of chronic patients in the facilities.

A safety net is created at diagnosis where newly diagnosed patients are to be seen by doctors to initiate them on chronic medication. The patients seen and managed by PNs (271 encounters) showed $63.5 \%$ PN compliance with drug management according to the STG, versus doctors' performance of $56.6 \%$. Coleman et al. ${ }^{15}$ had very similar findings with a broader spectrum of chronic illnesses being treated by nurses in PHC in SA.

Nelson and Knapp, ${ }^{21}$ focusing on the most frequently prescribed antihypertensive drug classes, concluded that prescribing patterns were generally consistent with guideline recommendations. However, most physicians used first-line agents that were inconsistent with the national guideline recommendations, regardless of their familiarity with the guidelines. For example, they complied with drug classes, e.g. diuretics, but prescribed a diuretic not recommended by guidelines. The doctors in this study were also less consistent than the nurses in following the EDL regarding drug management.

Of the 21 patients selected for the study the majority were men (57\%). The general trend regarding gender is that women are usually in the majority as in the two SA population studies done in 1988 and 2003 and this deviation from the usual norm is probably by chance given the small sample size.22 It should be emphasised though that identifying men with hypertension and controlling them can avert complications since men carry a higher cardiovascular risk than women. ${ }^{23}$ It was regrettable that $56 \%$ of clients were not advised on any form of non-drug management and only $10 \%$ had documented encounters regarding diet and exercise as these are the major contributors toward obesity, which in turns impacts on cardiovascular illness. ${ }^{23}$

Of the 21 patients 20 were checked for their weight and only 12 checked for height, making assessment of BMI possible in only $57 \%$. The mean BMI was 28 which is classified as obesity. A cardiovascular risk assessment can only be made possible with proper assessment of predictors of risk including BMI. The age group reflects the category that is seen in public facilities.

The mean systolic and diastolic BP at diagnosis and follow-up of this study are higher than the previous two population studies done in South Africa though they cannot be compared given the big difference in sample size. ${ }^{22}$ The recorded BP levels of participants in the 2003 survey, particularly the diastolic BP, were much lower than those in 1998. The consequence of this is that the apparent prevalence rate of hypertension in 2003 was reduced by almost half.22

There were some systems errors noted in the study with urine dipsticks being out of stock and $60 \%$ of side room examination (urinalysis) was subsequently not done to rule out renal pathology. Unavailability of certain drugs also periodically influenced practice. EDL drugs were, however, mainly prescribed as per EDL guidelines. The accurate documentation of chronically ill patients was done relatively well as all patients had a standard chronic form in their files.

\section{Conclusions and recommendations}

This study highlighted the importance of continuous professional development in terms of an emphasis on international standards of diagnosis and non-drug management as well as ongoing training on the updated versions of the EDL. Self-reported studies have revealed how doctors demonstrate an inertia to act on elevated BP despite their awareness of guidelines. Nurses are the main service providers in PHC and it is encouraging to see the increased level of compliance in both diagnosis and management of this category compared with similar studies. ${ }^{2,4}$

Source documents need to be properly monitored and information verified. Peer review of data and management oversight are encouraged. Training of staff on the chronic patient record is critical for uniformity in terms of data collection.

The use of a standardised chronic form improves management of patients by simplifying collection and documentation of clinical information over a 12-month period.

The study did not succeed in achieving an adequate sample size to be able to generalise the results to the sub-district under study and other sub-districts in the province. There is an opportunity, however, to do a prospective study where all newly diagnosed patients can be properly followed up and assessed for compliance in terms of diagnosis and management.

\section{ORCID}

\section{Claire van Deventer (D) http://orcid.org/0000-0002-9944-663X}

\section{References}

1. Redon J, Erdine S, Böhm M, Ferri C, Kolloch R, Kreutz R, et al. Physician attitudes to blood pressure control. J Hypertens. 2011;29:1633-40. http://dx.doi.org/10.1097/HJH.0b013e328348c934

2. Hagemeister J, Schneider CA, Barabas S, Schadt R, Wassmer G, Mager $\mathrm{G}$, et al. Hypertension guidelines and their limitations- the impact of physicians' compliance as evaluated by guideline awareness. J Hypertens. 2001;19:2079-86. http://dx.doi.org/10.1097/00004872 200111000-00020

3. National Drug Policy for South Africa. 1996. [cited 2015 Mar] Available from: http://apps.who.int/medicinedocs/documents/s17744en/ s17744en.pdf

4. Cassimjee $M$, Suleman F. Adherence to hypertension treatment guidelines in state facilities in KwaZulu-Natal, South Africa. J Eval Clin Pract. 2009;15:1077-81. http://dx.doi.org/10.1111/j.13652753.2009.01123.x

5. Horton R. Non-communicable diseases 2015-2025. Lancet. 2013;9866(381):507-98.

6. Seedat YK, Rayner BL, Veriava Y. South African hypertension practice guideline 2014: review article. Cardiovasc J Afr. 2014;25(6):288-94. http://dx.doi.org/10.5830/CVJA-2014-062

7. National Essential Drugs List committee. Primary health care standard treatment guideline and essential medicines list. 5th Edition. Pretoria: Author; 2014.

8. Statistics South Africa 2012. 2011 census South Africa. [cited 2013 Apr] Available from: http://www.census2011.co.za

9. Kjeldsen SE, Hedner T, Jamerson K, et al. Hypertension optimal treatment (HOT) study: home blood pressure in treated hypertensive subjects. Hypertension. 1998;31:1014-20. http://dx.doi. org/10.1161/01.HYP.31.4.1014

10. SHEP Cooperative Research Group. Prevention of stroke by antihypertensive drug treatment in older persons with isolated systolic hypertension. Final results of the Systolic Hypertension in the Elderly Program (SHEP). JAMA. 1991 Jun;26(265):3255-64. 
11. Dahlöf $B$, Hansson L, Lindholm LH, et al. Morbidity and mortality in the Swedish trial in old patients with hypertension (STOP-Hypertension). Lancet. 1991;338(8778):1281-5. http://dx.doi.org/10.1016/01406736(91)92589-T

12. Kaplan NM. The 6th joint national committee report (JNC-6): new guidelines for hypertension therapy from the USA. Keio J Med. 1998 Jun;47(2):99-105. http://dx.doi.org/10.2302/kjm.47.99

13. The Guidelines subcommittee of the WHO-ISH mild hypertension liaison committee. 1999 World Health organization- International Society of Hypertension guidelines for the management of hypertension. J Hypertens. 1999;17(2):151-83.

14. WHO Global NCD Action Plan 2013-2020. [cited 2016 May]. Available from: http://apps.who.int/iris/bitstream/10665/94384/1/978924150 6236_eng.pdf?ua=1

15. Coleman R, Gill G, Wilkinson D. Noncommunicable disease management in resource-poor settings: a primary care model from rural South Africa. Bull World Health Organ. 1998;76:633-40. pmid:10191559.

16. Milchak JL, Carter BL, James PA, et al. Measuring adherence to practice guidelines for the management of hypertension: an evaluation of the literature. Hypertension. 2004;44(5):602-8. http://dx.doi.org/10.1161/01.HYP.0000144100.29945.5e

17. Their SL, Yu-Isenberg KS, Leas BF, et al. In chronic disease nationwide data show poor adherence by patients to medications and by physicians to guidelines. Mange Care. 2008;17(2):48-52.
18. Chukwuani CM, Olugboji A. Improving access to essential drugs for rural communities in Nigeria: the bamako initiative re-visited. Pharm World Sci. 2006;28(2):91-5. http://dx.doi.org/10.1007/s11096-006-9010-1

19. Steyn K, Bradshaw D, Norman R, et al. Determinants and treatment of hypertension in South Africans: the first demographic and health survey. $S$ Afr Med J [Internet]. 2008;98(5):376-80 [cited 2017 Jan 10]. Available from http://www.scielo.org.za/scielo.php?script=sci_arttext\&pid=S025695742008000500021\&lng=en\&nrm=iso. ISSN 2078-5135.

20. Hyman DJ, Pavlik VN. Self-reported hypertension treatment practices among primary care physicians. Arch Intern Med. 2000;160:2281-6. http://dx.doi.org/10.1001/archinte.160.15.2281

21. Nelson CR, Knapp DA. Trends in antihypertensive drug therapy of ambulatory patients by US office-based physicians. Hypertension. 2000;36:600-3. http://dx.doi.org/10.1161/01.HYP.36.4.600

22. South Africa Demographic and Health Survey 2003. Department of Health. Pretoria: Author; 2007.

23. Hubert HB, Feinleib M, McNamara PM, et al. Obesity as an independent risk factor for heart disease: a 26 year follow up of participants in the Framingham heart study. Circulation. 1983;67(5):968. http://dx.doi. org/10.1161/01.CIR.67.5.968

Received: 31-07-2016 Accepted: 05-12-2016 